\title{
Quantification of Water Content and Grace of Succulence in Plants
}

\author{
Mauricio Cezar Resende Leite Junior,* Hermes Soares Rocha, Denis Leocádio Teixeira, Luciane da Costa Barbé, \\ Leonardo Barros Dobbss, Hellen Pinto Ferreira Deckers, Sérgio Macedo Silva
}

Adjunct Professor at the Federal University of Vales do Jequitinhonha and Mucuri / UFVJM, Brazil

\begin{abstract}
Water is the liquid of life, given its importance, this fluid is essential in the vegetative development of plants. Thus, the physiological actions of the drugs were made in the form of water, which are among the tasks on the plant can be useful, there is no protoplasm, gas exchange and thermal regulation of plants. Moreover, the relationship between plant, soil and atmosphere is integrally linked to water, which is the essential agent for this system. Due to its importance, it is essential to quantify the amount of water present in the plant, for subsequent physiological and relationship analysis with the soil and the atmosphere. Water content and degree of juiciness were performed in leaf, stem and root organs, comparing the results to better understand the percentage of water present in each organ.
\end{abstract}

Keywords: water deficit, vegetation, plant physiology, protoplasm

\section{Introduction}

Water is fundamental for life, it is considered among the most essential for life on the Earth's surface. ${ }^{1}$ This solvent has an anointing with several physiological processes of vegetables, such as transpiration, translocation of solutes, among others. ${ }^{2}$ How vegetables are distributed on planet Earth is linked to water availability more than any other factor. ${ }^{3}$ The basic structure of any living organism is the cell, however, as the plants are organized, variation can occur, ranging from simple single-cell structures to complex multicellular structures, with numerous different organs and physiological actions. ${ }^{1}$

Water has several functions linked to the physiological process of plants, as the main constituent of protoplasm, it participates in metabolic reactions of synthesis or degradation, a source of protons and electrons in photosynthesis, a universal solvent, it is a means of transporting materials and nutrients, through xylem and phloem.
In addition, it helps the absorption of gases and materials through the film that establishes root / soil, thermal regulator of plants, guarantees the turgidity of tissues, organs and even the shape of some plants, it is responsible for the movement of stoma opening and closing. ${ }^{2}$

The study and transformation of a real situation or problem involving the water-soil-plant-atmosphere system into techniques, models and solutions, allows to explain and understand the physical phenomena involved more deeply, make predictions and make decisions for research and activities in the soil and biosystems engineering. ${ }^{3}$

The dynamics of water in the plant are made by transport equations, water absorption by the roots; transportation in the xylem; rise of sap, among these equations stands out the water content in the plant and the degree of succulence. ${ }^{2}$

\begin{tabular}{|l|l|}
\hline Quick Response Code: & *Corresponding author: Mauricio Cezar Resende Leite Junior, Adjunct Professor at the Fed- \\
eral University of Vales do Jequitinhonha and Mucuri/UFVJM, Brazil \\
Received: 18 December, 2020 \\
Citation: Mauricio CRLJ, Hermes SR, Denis LT, Luciane da CB, Leonardo BD, Hellen PFD, et \\
al. Quantification of Water Content and Grace of Succulence in Plants. Glob Scient Res Env Sci. \\
\hline 2021;1(1):1-3. DOI: 10.53902/GSRES.2021.01.000505
\end{tabular}


The flows of water vapor and carbon dioxide between plants and the atmosphere and energy flows between the plant and the atmosphere are important to analyze how the water, plant, soil and atmosphere system works. ${ }^{1}$

With the water balance of the plant it is possible to notice factors that affect the absorption and loss of water by the plant and the water balance of the plant, which is the focus of the article, allows to identify vegetable indicators of water deficit. ${ }^{2}$

Given the importance of water in the plant, it is of great value that the quantification of water present in the plant occurs. ${ }^{4}$

The purpose of this article is to quantify the water content in the plant, the degree of succulence, leaves, stem and root collected at the Federal University of Vales Jequitinhonha and Mucuri, campus Unaí-MG.

The article is divided into 5 main sections, and the initial introduction section provides a brief history on the subject covered throughout the manuscript, the topic on material and methods addresses the methodology used and the research procedures used, the results and Discussions demonstrate the results obtained during the development of the research and compare them with results already available in other publications, the conclusions answer the initial objectives of the work and the bibliography brings all the authors who were the source of research for the development of the project.

\section{Material and Methods}

Leaves, stems and roots were collected at the Federal University of Vales Jequitinhonha and Mucuri, campus Unaí-MG, looking for these organs in plants with marked developmental characteristics, with no yellow color.

Right after the collection, the area of the collected organs was determined, from an A4 size sheet, and with the aid of a ruler, where the area that was occupied by the leaves, roots and stems was determined, as shown in Figure 1\&2. Soon after, all the organs were weighed on a precision scale, and their values were recorded.

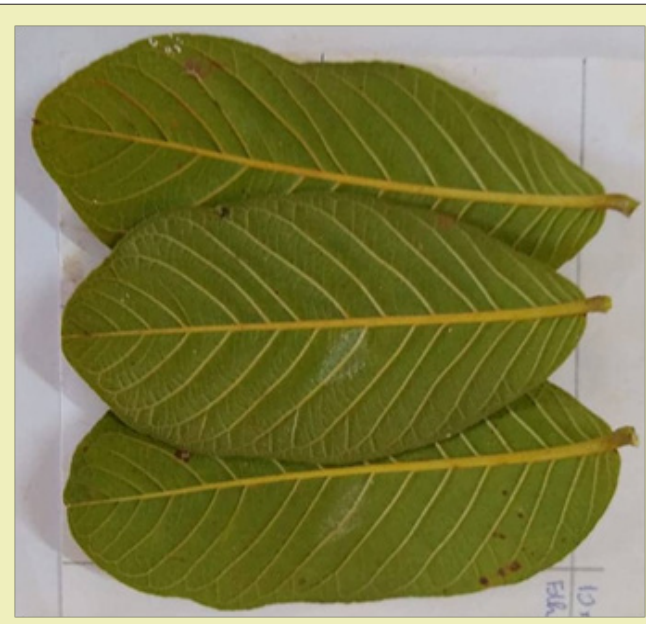

Figure 1: Leaves collected.

Source: Author

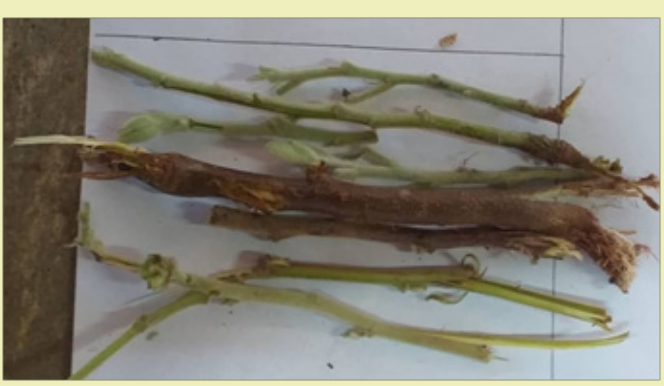

Figure 2: Stems collected.

Source: Author

Then each organ was placed in a paper package and immediately taken to dry in an oven with forced air circulation, at a temperature of $65^{\circ} \mathrm{C}$ and left in an oven for 24 hours. After 24 hours the material was removed from the oven and weighed again and the values recorded.

With that, the formulas were used to determine the water content and degree of succulence, according to equations 1 and 2 .

$\mathrm{TA}=100 \times(\mathrm{MF}-\mathrm{MS}) / \mathrm{MF}$

Where:

$\mathrm{TA}=$ Water content in the plant.

$\mathrm{MF}=$ Fresh Dough .

MS = Dry Mass

$\mathrm{GS}=(\mathrm{MF}-\mathrm{MS}) / \mathrm{A}$

Where:

GS = Degree of Suculence.

$\mathrm{MF}=$ Fresh Dough .

MS = Dry Mass.

$\mathrm{A}=$ Leaf area.

\section{Results and Discussion}

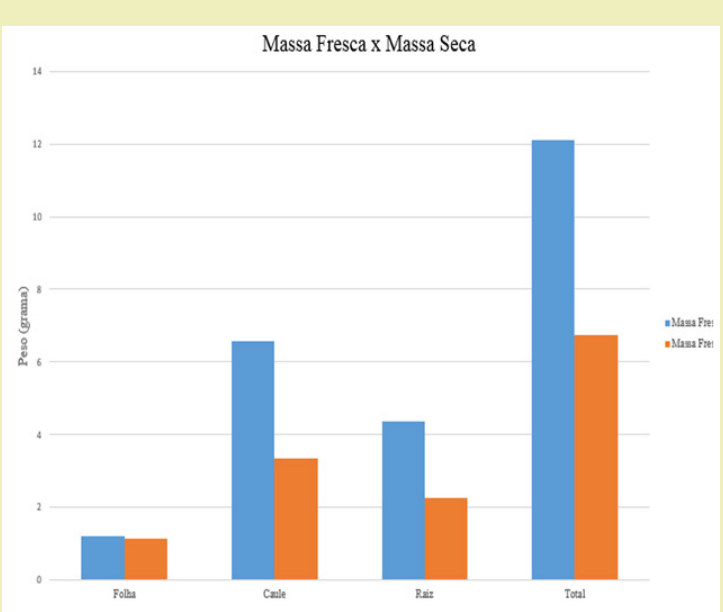

Graph 1: Comparison between fresh and dry pasta. Source: Author 
The weights acquired from weighing the fresh and dry mass on the precision scale, show a decrease in values, which was expected, due to the loss of water in the greenhouse, contained in the leaves, roots and stems, noted that the percentage of loss the water content Table 1: Weighing of plant organs and percentage of weight loss.

\begin{tabular}{|c|c|c|c|c|}
\hline Plant Organ & Fresh mass (g) & Dry Mass (g) & Difference(g) & Percentage of perch (\%) \\
\hline leaf & 11864 & 11349 & 0,0515 & 43409 \\
\hline Stalk & 65814 & 33319 & 32495 & 493740 \\
\hline Root & 43598 & 22579 & 21019 & 482109 \\
\hline Tot & 121276 & 67247 & 54029 & 445504 \\
\hline
\end{tabular}

Source: Author

In the degree of succulence, it is noticed that the stem has a higher degree than the other organs, which is confirmed with the calculation of water content, while the leaf can be defined as very

Table 2: Degree of succulence of the plant's organs. in the organs was lower on the leaf, accounting for $4.3409 \%$, while the highest was on the stem with $49.3740 \%$, and the total loss is 44.5504\%, as shown in Table 1 and Graph 1.

\begin{tabular}{|c|c|c|c|c|}
\hline Plant Organ & Fresh mass $\mathbf{( g )}$ & Dry Mass $\mathbf{( g )}$ & Area foliar $\left.\mathbf{( m}^{\mathbf{2}}\right)$ & Degree of succulence \\
\hline leaf & 1.1864 & 11349 & 1 & 0,0515 \\
\hline Stalk & 6.5814 & 3.3319 & 0,6 & 54158 \\
\hline Root & 43598 & 22579 & 0,5 & 42038 \\
\hline Tot & 121276 & 67247 & - & - \\
\hline
\end{tabular}

Source: Author

\section{Conclusion}

It was noted that from the calculations mentioned, it is possible to determine the degree of succulence and the water content in the plants. Which is a great help for calculating potentials and studies of the relationship between water, plant, soil and atmosphere. From these data you can know if the plant is suffering from water stress.

\section{Acknowledgments}

None.

\section{Funding}

None. little succulent since it does not reach the degree 1 of succulence, according to Table 2 .

\section{Conflicts of interest}

Author declares that there is no conflict of interest.

\section{References}

1. Pimentel C. The relationship of the plant to water. Seropedic. Rio de Janeiro: EDUR. 2004.

2. Ferreira. LGR Plant Physiology: water relations. Fortaleza, EUFC. 1992. $138 \mathrm{p}$.

3. Peixoto, CP Class notes. Monographs of the Courses in Plant Physiology and Production Physiology. Cruz das Almas. AGR/UFBA. 2002.

4. Tuner NC. Adaptation to water deficits: a changing perpective. Austr J Plant Physiol. 1986;43:175-190. 